\title{
Corporate Culture
}

\section{IN BANKING}

\section{INTRODUCTION}

Culture can be a very complex issue as it involves behaviours and attitudes. But efforts should be made by financial institutions and by supervisors to understand an institution's culture and how it affects safety and soundness. While various definitions of culture exist, supervisors are focusing on the institution's norms, attitudes, and behaviours related to risk awareness, risk taking, and risk management or the institution's risk culture.

(Financial Stability Board 2014)

The issue of corporate culture in banking has surfaced in recent discussions as a topic of pivotal significance for addressing two concerns: restoring public trust in the banking system and enhancing financial stability. ${ }^{1}$ With more than $\$ 100$ billion in fines imposed on the largest financial institutions since the financial crisis, there is now a growing suspicion that ethical lapses in banking are not just the outcome of a few "bad apples" - such as rogue traders-but rather a reflection of systematic weaknesses. The lack of confidence in banking engendered by such mistrust may

\footnotetext{
${ }^{1}$ See Federal Reserve Bank of New York President William Dudley's speech "Enhancing Financial Stability by Improving Culture in the Financial Services Industry," October 20, 2014. Available at http://www.newyorkfed.org/ newsevents/speeches/2014/dud141020a.html.
}

invite more intrusive regulation, which could reduce risk but may also restrict lending. Given how essential banks are for economic growth and their complementarity with financial markets for channeling capital from savers to investors, this issue is of broad economic interest. ${ }^{2}$

In this dialogue, considerable attention has been paid to executive compensation in banking, with the prevailing view being that improperly structured pay was one of the culprits in the recent financial crisis (see, for example, Curry [2014]). This issue was addressed in the Dodd-Frank Act, which requires regulatory agencies to implement appropriate incentive-based compensation rules covering institutions with assets of $\$ 1$ billion or more. The Office of the Comptroller of the Currency, for example, published a proposed rule in 2011 that is based on three principles: (1) incentive-based compensation should balance risk and reward, and should include deferred compensation and other mechanisms to reduce the sensitivity of compensation to short-term results; (2) compensation plans should be compatible with effective controls and risk management; and (3) incentive-based compensation should be supported by strong corporate governance.

Focus on compensation is a useful first step. But as important as pay is for driving employee behavior, it is but one piece of the puzzle, and excessive reliance on compensation may actually distract attention from other important determinants of the decisions banks make. I am heartened by the growing

${ }^{2}$ See, for example, Song and Thakor (2010).

The author thanks Hamid Mehran for helpful comments. The views expressed are those of the author and do not necessarily reflect the position of the Federal Reserve Bank of New York or the Federal Reserve System.

To view the author's disclosure statement, visit https://www.newyorkfed.org/ research/author_disclosure/ad_epr_2016_corporate-culture_thakor.html. 
recognition of bank regulators in the United States and Europe that organizational culture in banking is a crucially important factor in generating positive observable outcomes in banking. Culture not only determines the efficacy of compensation in influencing employee behavior, but it can also induce employees to work in a manner consistent with the stated values of the organization, particularly when achieving this outcome via formal contracts may be either costlyowing to bargaining, asymmetric information, and imperfect state observability—or infeasible (see Kreps [1990] and Song and Thakor [2016]). Cultural difference means that the same incentive-based compensation scheme can produce different behavioral outcomes in two banks.

It is easy to see, however, why culture has not been a big part of banking regulation. Variables like capital ratios and compensation are tangible and visible, so it is easy to target them in the formulation of regulations. Culture, by contrast, is a nebulous concept that often means different things to different people. Because it is fuzzy, culture tends to be overlooked. Moreover, we have a vast body of research on capital

\section{Culture not only determines the efficacy of compensation in influencing employee behavior, but it can also induce employees to work in a manner consistent with the stated values of the organization, particularly when achieving this outcome via formal contracts may be either costly ... or infeasible.}

requirements and incentive-based compensation, but precious little on culture, at least in economics. This omission too adds to the reasons why culture has received relatively scant attention until recently in regulatory discourse. Yet, the inattention to the significance of culture has limited our ability to design regulations that proactively cope with foreseeable problems. It is unlikely, however, that future banking regulation will operate in a culture vacuum.

The purpose of this article is threefold. The first objective is to define culture and briefly consider the way culture has been viewed in the economics and organizational behavior literatures. The second goal is to introduce a framework to diagnose the attributes of a culture, formulate views about the preferred culture of an organization, and examine practical ways in which a bank can undertake a change from the current to the preferred culture. The third purpose is to discuss the regulatory policy implications of this way of thinking about bank culture.

This article draws its inspiration and many ideas from the previous work done on organizational culture. Kreps (1990) views culture, in a game-theoretic sense, as serving two goals: as a coordinating mechanism when there are multiple equilibria and as a way to deal with unforeseen contingencies. In particular, he emphasizes the role that culture can play when inducing cooperation through formal contracts is costly or infeasible because of bargaining costs, moral hazard, and asymmetric information. Repeated interactions can help bring about outcomes that formal contracts cannot achieve efficiently, but they often generate multiple equilibria, leaving outcomes unpredictable. When multiple equilibria are possible, it means that we cannot pin down theoretically which equilibrium outcome will occur, which some interpret as a kind of instability. Whether we view it as instability or not, it is at the very least something that represents a diminished ability to predict outcomes for any given set of actions by individuals and firms. In Kreps' view, a strong organizational culture can facilitate the elimination of undesirable Nash equilibria. His work has important messages on two fronts. First, it offers a word of caution against relying excessively on formal compensation contracts in banking. Second, it makes the point that absent a strong culture as a coordinating mechanism, beliefs about the actions (such as misbehavior) of others can induce employees to behave unethically or take excessive risks.

Cremer (1993) argues that an organization's culture is knowledge shared by the members of the organization, but not the general public. ${ }^{3}$ Culture acts as a substitute for explicit communication by providing a common language, shared knowledge of the facts, and shared knowledge of behavioral rules. Thus, with a strong culture, individual employees need not invest in acquiring organization-specific knowledge of rules. One result is that there are decreasing returns to scale when it comes to the benefits of culture. So as the organization grows larger and more complex, it is likely to develop subcultures in different divisions or business units. An important implication for banking is that large and complex financial services companies are likely to have a bigger challenge developing a uniform culture that guides the actions of all employees.

Hermalin (2001) describes culture as being either weak or strong and develops a model in which firms with strong cultures produce more in equilibrium than firms with weak cultures. The choice of strong versus weak culture is characterized as a choice between a high-fixed-cost,

${ }^{3}$ Lazear (1995) focuses on culture as shared preferences or beliefs that arise from an evolutionary process within firms. 
low-marginal-cost regime (strong culture) and a low-fixedcost, high-marginal-cost regime (weak culture). An important result is that the cost of developing a strong culture can be determined by the firm, but the benefit depends on the competitive environment. An implication for banking is that the actors in the industry must collaborate-or be induced to do so by regulators - to develop strong organizational cultures, or else short-term competitive pressures may diminish the value an individual bank attaches to developing a strong culture.

Akerlof and Kranton (2010) do not directly address the issue of organizational culture, but touch upon a related idea. They develop the concept of "identity economics," in which an individual's actions depend on the identity an individual associates with himself. Identity enters the individual's utility function directly, and individuals can identify themselves as being firm “insiders" or “outsiders." Insiders tend to expend high effort and outsiders low effort. A key result is that the presence of identity utility reduces the wage differential needed to induce the agent to expend high effort. The takeaway for banking is that culture may be a mechanism for changing the individual's identity, and may help the bank to rely less on compensation strategy to encourage desired behavior.

Van den Steen (2010a) develops an interesting theory of culture based on two important ideas. The first idea, familiar from previous research, is that culture is about shared values and beliefs. The twist, though, is that beliefs may be heterogeneous, and this divergence can lead to disagreement about the right course of action. ${ }^{4} \mathrm{He}$ argues that corporate culture

\section{Inattention to the significance of culture has limited our ability to design regulations that proactively cope with forseeable problems. It is unlikely, however, that future banking regulation will operate in a culture vacuum.}

"homogenizes" beliefs in three ways: screening in hiring (employees are chosen based on whether they share the beliefs that guide the organization, and they work harder knowing others do also); self-sorting (the employee's utility depends on her manager's actions); and joint learning. A key result is that corporate culture is stronger in older, smaller, and more successful (valuable) firms. Implications for banks are that growth

${ }^{4}$ See also Boot, Gopalan, and Thakor $(2006,2008)$. in size may be costly from the standpoint of culture, and that high charter values may be a significant ingredient in strong banking cultures. ${ }^{5}$

In a companion paper, Van den Steen (2010b) uses the same notion of culture as a set of shared beliefs and starts with the result that shared beliefs lead to increased delegation, higher utility, more effort, and less-biased communication. $\mathrm{He}$ then shows that a merger generally brings together two internally homogeneous groups with beliefs and preferences that differ. As a consequence, the extent to which employees in the merged firm might share beliefs is lower than what it was in each firm before the merger. Thus, agency problems are higher in the combined firm. One thought-provoking implication is that regulators ought to consider the congruence of cultures when evaluating proposed bank mergers. ${ }^{6}$

While the focus in economics has been on explaining why culture matters for economic outcomes, there is an older and more extensive literature in organizational behavior that views culture as a mediating, endogenously chosen variable that affects individual and group behavior. Although less familiar to economists, the organizational behavior research has had greater direct impact than work in economics in terms of its use in companies.

The organizational behavior literature on culture is vast. I will not discuss it extensively here since my discussion of the Competing Values Framework (CVF) later in this article captures many of the key elements that have been covered in this field of research. Useful references are Deal and Kennedy (1982), Peters and Waterman (1982), Cartwright and Cooper (1993), and Cameron and Quinn (2011). In a nutshell, this literature defines culture in terms of the descriptive categorizations of behavior associated with specific cultures, so that organizational leaders can predict more effectively how people will behave in a given culture and be influenced by explicit incentive-based compensation policies. ${ }^{7}$ The focus is thus on exploring the drivers and design of a culture. The exercise is normative in nature, and useful for leaders of banks who wish to understand how to develop a specific culture, as well as for banking regulators and supervisors who want to understand the kinds of behaviors a bank can be predicted to exhibit, given a specific culture.

${ }^{5}$ This is reminiscent of Keeley (1990), who provided empirical evidence that banks with high charter values take less risk.

${ }^{6}$ Fiordelisi and Martelli (2011) examine the dependence of merger success in banking on the cultures of the merging banks.

${ }^{7}$ Bouwman (2013) provides a more extensive discussion. 
The rest of this article is organized as follows. Section 2 defines culture and introduces the Competing Values Framework as an example of a framework for understanding culture. Section 3 extracts the main lessons of the CVF and combines them with insights from the economics literature to build a set of considerations for bank executives and boards as well as for bank regulators and supervisors. Section 4 summarizes key findings.

\section{A Framework for Culture}

\subsection{The Definition of Culture and the Challenge of Identifying Culture}

I define culture as the collective assumptions, expectations, and values that reflect the explicit and implicit rules determining how people think and behave within the organization. Culture includes a set of implicit contracts that enable the organization to delegate more effectively. Because the employees have shared (homogenous) beliefs when the organization has a strong culture (Van den Steen 2010a) and employees use similar, simplified rules for decision making (Cremer 1993), it becomes easier for organizational leaders to delegate tasks to subordinates.

What the research shows is that when culture is aligned with strategy, it facilitates value creation and ensures more effective execution of strategy (see Cameron, DeGraff, Quinn, and Thakor [2014]). Most organizations grasp this. However, understanding is not enough-leaders must know how to diagnose and change the culture of the organization to achieve optimal performance.

This point is where things become difficult. Because culture is such a nebulous concept, it is often difficult for leaders to think about it in tangible terms, so the notion of culture sometimes ends up being blended into the organization's statement of values or ethical behavior. While the values that the organization cherishes do affect its culture, this commingling of ethical behavior guidelines and culture into one expanded statement of values means that most employees will view culture merely as a set of guidelines to avoid unethical behavior-something nice to put on posters or walls, but hardly a guide for day-to-day decision making. In organizations where this happens, culture has little impact on the execution of strategy.

Culture is more than just a set of guidelines that define ethical behavior in the organization. As The Economist noted in an article discussing the way banks are run,
"The overall culture of the organization matters as much as the experience of the top brass, particularly when it

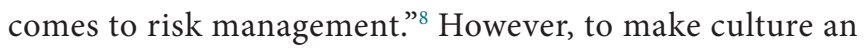
integral part of how the organization behaves, the following points are important to note:

- The culture of the organization must support the execution of the organization's growth strategy.

- The strategy of the organization must specify how resources-human and financial-will be allocated to various activities.

- An important consideration in assessing leadership capabilities of employees should be their respect for and practice of the culture.

When these three conditions are met, culture is actually "practiced" in the sense that day-to-day operating decisions are made in a manner consistent with the organization's strategy and its way of thinking. However, it should be apparent that for these conditions to be met, there must be a shared understanding of what culture is. To start, leaders must identify the culture of the organization and then communicate it clearly up and down the line in succinct, easily comprehended language. This challenge, in my view, is a major one because of the inherent complexity of organizational culture and the myriad ways in which culture operates within the organization. How can such complexity be communicated in simple terms so that culture becomes a part of the daily rhythm of organizational decision making?

Cameron, DeGraff, Quinn, and Thakor (2014) point out that, when it comes to understanding inherently complex concepts, one must seek the help of a "master" rather than an "expert." An expert is cognizant of the complexity of a phenomenon and therefore aware of its multiple and complicated elements. The expert's explanation of the phenomenon is elaborate and intricate, so the complexity of the idea is conveyed, but not in simple terms. In contrast, a master understands a concept in so much greater detail and depth than the expert that he is able to explain it in very plain terms and in a manner that the whole organization can grasp. In the next subsection, I describe a framework that has been used extensively to define and communicate culture. This approach should be viewed merely as an example. There may be other frameworks for diagnosing culture that may be used as well, as long as they are simple and effective.

8 “Tightrope Artists," The Economist, May 15, 2008. 


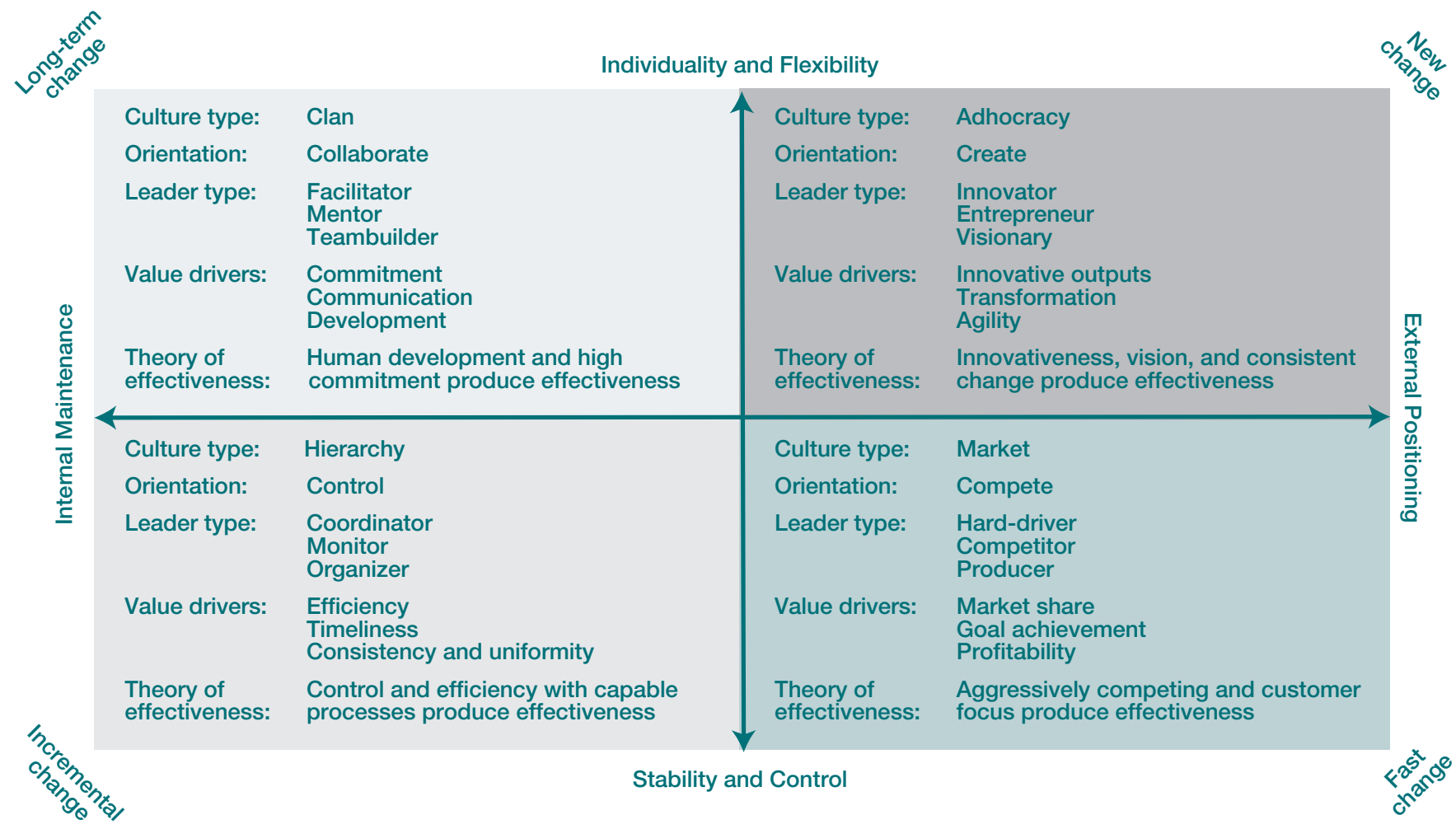

\subsection{The Competing Values Framework}

The Competing Values Framework, depicted in Exhibit 1, provides a way to characterize organizational culture in simple, easy-to-communicate terms. Developed in the organizational behavior literature (see, for example, Quinn and Cameron [1983], Quinn and Rohrbaugh [1983], Quinn [1988], and Cameron and Quinn [2011]), this framework is widely used by organizations (see, for example, ten Have et al. [2003]).

The CVF begins with the observation that organizations engage in countless activities to create value, but the vast majority of these activities can be put into one of the four categories or quadrants depicted in the exhibit above: Collaborate (Clan), Control (Hierarchy), Compete (Market), and Create (Adhocracy). The action verbs are the labels from Cameron, DeGraff, Quinn, and Thakor (2014). We have found them to be more useful when working with organizations on cultural diagnosis and intervention than the words in the parentheses, which are the labels from the original research in organizational behavior. I will now discuss each quadrant.
Collaborate: Value-enhancing activities in this quadrant deal with building human competencies, developing people, and encouraging a collaborative environment. The approach to change in this quadrant is deliberate and thoughtful because the reliance is on consensual and cooperative processes. Leadership development, employee satisfaction and morale, the creation of cross-functional work groups, employee retention, teamwork, and decentralized decision making are all areas of focus in this quadrant. Organizational effectiveness is associated with human capital development and high levels of employee engagement.

Control: Value-enhancing activities in this quadrant include the pursuit of improvements in efficiency through better processes. The goal is to make things better, at lower cost, and with less risk. One of the hallmarks of this category is achieving a high degree of statistical predictability in outcomes. Organizational effectiveness is associated with capable processes, measurement, and control. Examples of activities in this quadrant include risk management, auditing, planning, statistical process control, Six Sigma and Lean Six Sigma 
techniques for improving manufacturing processes, and so on. These activities make the organization function more smoothly, efficiently, and predictably.

Compete: Value-enhancing activities involve being aggressive and forceful in the pursuit of competitiveness. Activities in this quadrant involve monitoring market signals and emphasizing interactions with external stakeholders, customers, and competitors. The focus is on customer satisfaction and delivering shareholder value. A mantra here might be "compete hard, move fast, and play to win." Organizational effectiveness is associated with achieving desired outcomessuch as profits, market share, and shareholder value-with speed. Market domination is a goal.

Create: Value-enhancing activities in this quadrant involve innovation in the organization's products and services. A mantra of this quadrant might be "create, innovate, and envision the future." Organizations that excel in this category effectively handle discontinuity, change, and risk. They allow freedom of thought and action among employees, so thoughtful "rule breaking" and stretching beyond the existing boundaries are commonplace. Organizational effectiveness is associated with entrepreneurship, vision, new ideas, and constant change.

\subsection{Tensions within the Framework}

To understand the CVF, one must examine the similarities and differences between the quadrants. Consider first the Collaborate and Control quadrants, both of which are internally focused. Collaborate focuses on the "human capital" within the organization-its employees and their harmony, retention and morale, teams, leadership development, and so on. Control focuses on the "process capital" within the organization-the manner in which internal processes are used to achieve efficiency and predictability of outcomes.

By contrast, the Compete and Create quadrants are outwardly focused. Compete is focused on the customers, competitors, markets, and opportunities that exist today, while Create is focused on the customers, competitors, markets, and opportunities that will exist in the future.

So one dimension of similarity and difference is whether there is an internal or external focus. In this dichotomy, Collaborate and Control stand on one side-characterized by an internal focus-and Compete and Create stand on the other side-characterized by an external focus.

A second dimension along which one can compare the quadrants is in the degree of their focus on stability and control as against individuality and flexibility. On this dimension, Control and Compete share an emphasis on stability and
Exhiвiт 2

A Competing Values Framework Culture Map

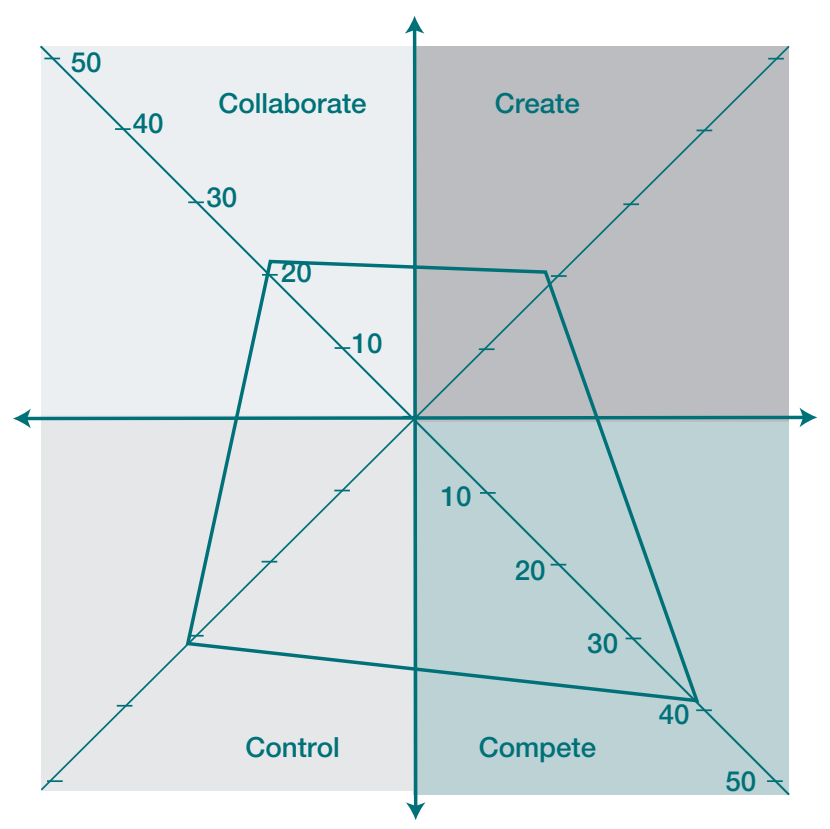

control. These quadrants place importance on tangible and measurable outputs, where the rules for how best to operate are well known. Leadership style tends to be prescriptive, and organizations often have detailed manuals describing how things should be done. The time horizon for achieving results is typically short. By contrast, Collaborate and Create involve a great deal more individuality and flexibility. The rules of success are not as well defined, and more experimentation is encouraged. Leadership style is more participative than prescriptive, and the time horizon for achieving results is typically longer.

A key insight of the CVF is that diagonally opposite quadrants have nothing in common. That is, Collaborate shares no similarity with Compete, and Control shares nothing with Create. Indeed, one can make an even stronger statement: at the margin, these quadrants pull the organization in opposite directions. Any resources allocated to one quadrant pull the organization away from its diagonal opposite. In a sense, the quadrants represent competing forms of value creation. This split creates inherent tensions within the organization, as stakeholders at opposite ends engage in a veritable tug-of-war as they compete for resources to devote to the activities they believe will create the most value. These competing views and beliefs about what creates value can be considered similar to the disagreement stemming from heterogeneity described by Van den Steen (2010a, 2010b). 
When an organization chooses its culture, it is effectively deciding its relative degrees of emphasis on the four quadrants in Exhibit 2. This picture of culture would typically be constructed on the basis of a survey of employees in the organization, using a diagnostic instrument (see Cameron and Quinn [2011]). The usefulness of this pictorial depiction of culture is that:

- it can communicate the organization's culture to all key stakeholders;

- it clarifies how the organization will allocate resources to execute its growth strategy;

- it becomes a guide for the organization's hiring, development, and retention processes; and

- it serves as a mechanism to coordinate beliefs and guide day-to-day decision making.

\subsection{Adapting the CVF to Analyze Credit Culture in a Bank}

The use of the CVF is not limited to analyzing the culture that supports the overall growth strategy of the organization; the framework can also be used to analyze specific aspects of the overall culture, such as those relating to the credit risk-management of the bank. ${ }^{9}$ Exhibit 3 shows what the four quadrants of the CVF would translate into when it comes to credit culture (which reflects the values, norms, and formal and informal practices that pertain to how the organization makes credit decisions and manages credit risk).

A credit culture that emphasizes Collaborate would be a partnership culture, one in which employees would find it beneficial to work in collaborative, cross-functional teams. This quality may perhaps be viewed as a dominant aspect of the culture that existed in U.S. investment banks before they became publicly traded corporations, and it is the culture that currently exists among Farm Credit System banks.

A credit culture that emphasizes Control would be a risk-minimization culture, in which a great deal of importance is placed on rigorous credit analysis and post-lending monitoring of adherence to covenants, with a low tolerance for default risk. Growth would be sacrificed in the interest of prudence and safety. There would be tight controls, and violations of process guidelines would not be tolerated.

\footnotetext{
${ }^{9}$ Clearly, the credit culture in a bank has to be consistent with the overall culture that supports its growth strategy. However, describing the credit culture separately enables a focus on details relating to the credit risk management of the bank.
}

Exнiвiт 3

\section{Credit Culture}

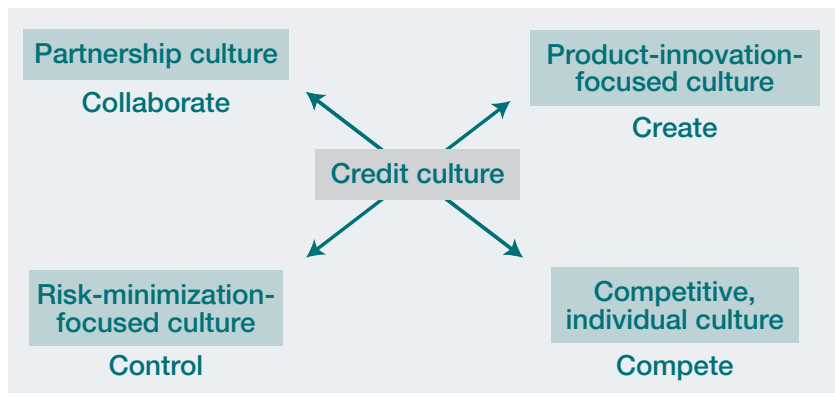

A credit culture that emphasizes Compete would be a competitive, individual-performance-oriented culture, in which employee bonuses depend on exceeding performance targets, the ratio of bonus to base pay would be high, and market share gains and revenue growth would be greatly valued. Such firms will display an appetite for acquisitions and will value decisive, fast-moving, and aggressive employees.

A credit culture that emphasizes Create would be one focused on product innovation and organic growth. In such an environment, experimentation with new products would be encouraged. So firms with this culture would extend securitization to new asset classes, devise new contracts providing an expanding array of individuals and firms with access to the credit market, design new instruments for hedging and transferring risk, and so on. The investment banking industry in the United States has been a leader in financial innovation because it places a greater degree of emphasis on product creation than its counterparts in other areas of the world. ${ }^{10}$

A key message of the CVF is that while most banks will have an organizational culture that spans all four quadrants, each bank will typically be strongest in one quadrant, and this strength will have a large influence on how the bank operates, where it is most successful, and what it finds most challenging. For example, a bank with a Create culture will consistently come out with new financial products and achieve a high level of organic growth, but will have the most difficulty maintaining consistent risk-control standards and eliminating regulatory compliance errors. Similarly, a bank with a Compete credit culture will be fiercely competitive in the marketplace, winning most of its market share battles, and will grow aggressively through acquisitions. Its biggest challenges will be creating trust

${ }^{10}$ Boot and Thakor (1997) develop a theory that explains why U.S. investment banks have been more successful in financial innovation than investment banks in Europe. 
among employees within the organization, achieving collaboration, and having a high employee retention rate.

\subsection{Diagnosing and Changing Culture Using the CVF}

The CVF enables any organization to assess its current culture as well as its preferred culture. Using a diagnostic instrument that has been validated by extensive research in organizational behavior, it is possible to conduct a survey of any subset of the organization's employees about organizational practices and individual behaviors. ${ }^{11}$ The responses can then be aggregated and averaged in order to produce a map of the current and preferred cultures, as shown in Exhibit 4.

The unbroken lines in the exhibit depict the current culture of the organization, and the broken lines depict the preferred culture. In this case, the organization wishes to shift from a focus on control and stability (the Control quadrant) to a focus on flexibility, collaboration (the Collaborate quadrant), and innovation (the Create quadrant). Knowing this goal, the organization can engage the organization in a discussion of how this change in culture can be achieved, a topic addressed in the next subsection.

The CVF is currently a leading method used in assessing organization culture. Several consulting firms have employed this framework to organize items on their climate and culture instruments (see, for example, DeGraff and Quinn [2006]).

\subsection{Levers for Changing Culture}

There are primarily four levers that must be pulled in order to change culture: performance metrics for judging individuals, projects, and business units; compensation; processes for decision making and resource allocation; and behaviors to encourage, tolerate, and punish.

Consider performance metrics. Many organizations recognize the importance of having their executives develop the leadership abilities of those who report to them, so that the individuals they supervise can become future leaders. However, mentoring and coaching are time-consuming activities, so quite often there is an under-provision of effort to this task. One organization that attaches high value to this activity altered performance metrics to encourage more investment of time and

\footnotetext{
${ }^{11}$ See Cameron and Quinn (2011) for a complete discussion of the Organizational Cultural Assessment Instrument. See Cameron, DeGraff, Quinn, and Thakor (2014) for a rebuttal of criticisms of the CVF in the organizational behavior literature.
}

ExHiBit 4

Changing Organizational Culture

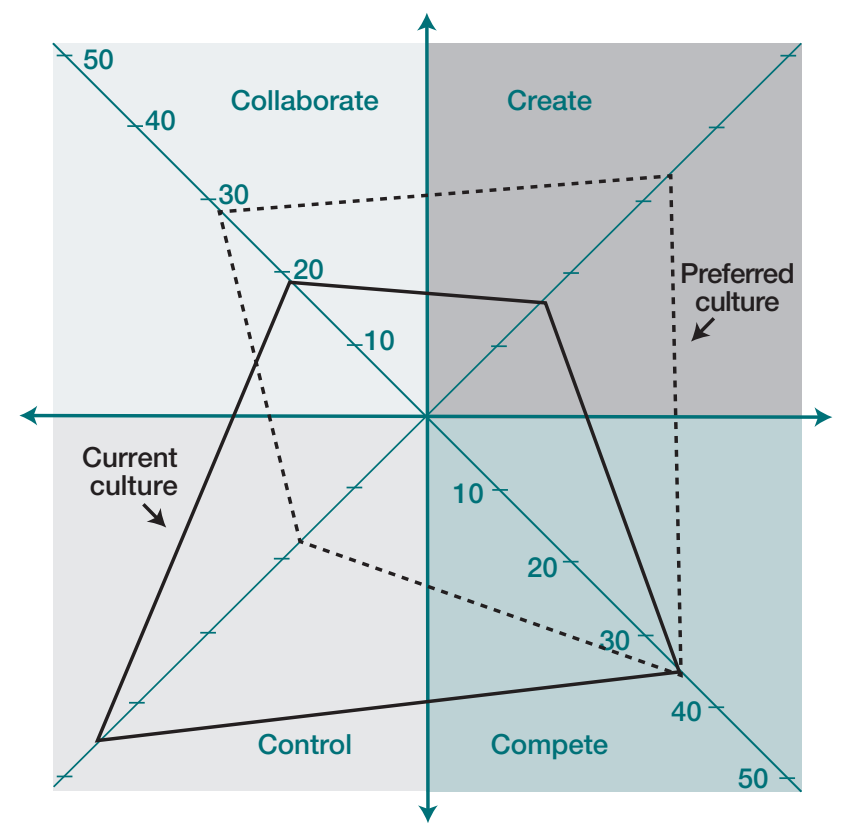

effort in this activity. Specifically, every leader, in collaboration with his or her supervisor, is asked annually to evaluate all direct reports on their readiness for leadership, specifically their readiness to replace their boss. Just as criteria can be set for promotion, they can also be prescribed for dismissal. ${ }^{12}$

Compensation design also has a big impact on how employees behave. In banking, there is a greater emphasis on return on equity (ROE) for computing executive bonuses than in any other industry. ${ }^{13}$ It is not surprising then that bankers are averse to higher capital requirements, since holding higher capital leads to a lower ROE, other things equal. Similarly, if loan officers are compensated for growth in loan volume, then they will have incentives to grow loan volume with far less emphasis on credit quality. ${ }^{14}$ A culture that emphasizes Collaborate and Create will wish to rely more on deferred compensation, perhaps imposing a longer compensation "duration." ${ }^{5}$

\footnotetext{
${ }^{12}$ As Jack Welch, former chairman and chief executive officer of General Electric, said in an interview with Stuart Varney on CEO Exchange in 2001, any organization that fails to root out and dismiss those who deliver great results but disrespect the culture cannot talk credibly about values.

${ }^{13}$ See Bennett, Gopalan, and Thakor (2012).

${ }^{14}$ See Acharya and Naqvi (2012) for a theory of how such compensation incentives for loan officers sow the seeds of crises.

${ }^{15}$ See Gopalan, Milbourn, Song, and Thakor (2014) for a definition of empirical evidence on compensation duration.
} 
Processes also matter for culture. For example, if an organization has numerous checks and balances in its resource allocation-typical of a strong Control culture-then its employees are unlikely to allocate significant resources to the pursuit of new products and services. A reason for this is that often there is considerable disagreement over whether an innovation is worth introducing. ${ }^{16}$

Finally, one should not underestimate the importance of the behaviors that leaders encourage, tolerate, and punish. If leaders are vocal about these behaviors and reinforce their views with action in terms of rewards and punishments, then they will be able to influence behavior that supports the preferred culture.

\section{IMPLICATIONS FOR BANKS, REgulators, AND SUPERVISORS}

In this section, I summarize the key lessons from the research on culture in economics and the CVF, discuss what leaders of banks and other financial services organizations can learn, and conclude with some takeaways for bank regulators and supervisors.

\subsection{Summary of Insights}

- A bank's culture must support the execution of its growth strategy, so that the culture affects all aspects of decision making. In other words, culture is much more than a statement about ethical behavior in banks; it is embedded in operations overall, such as how employees are hired, rewarded, and fired, how resources are allocated, and how risks and opportunities are managed.

- A strong culture can act as a coordination mechanism to eliminate Nash equilibria in which employees behave badly, and can help to achieve (desirable) outcomes that cannot be reached with formal contracts (such as incentive-based compensation) alone.

- It is more challenging to have a strong culture that operates effectively and consistently in a large and complex bank since subcultures are likely to emerge, leading employees to identify first with their business unit and then with the bank. Size creates the potential for more intrabank competition and behavior that is at odds with the bank's preferred culture.
- The benefit to a bank from developing a strong culture may depend on the competitive structure of the banking industry. Smaller, older, and more successful banks are likely to have stronger cultures.

- A strong culture can change an employee's "identity" in a positive way and allow the bank to rely less on incentive compensation to induce the desired behavior.

- If two banks with disparate cultures merge, there will be greater disagreement over decision making and higher agency costs than in either bank before the merger. This outcome is especially likely if the merging banks had cultures that were strong in diagonally opposite quadrants of the CVF.

- There is no such thing as a uniquely best culture. Because culture must support the bank's growth strategy and banks have different strategies, there is likely to be a distinct preferred culture for each bank.

- There are four types of cultural orientation: Collaborate, Control, Compete, and Create. In a two-by-two matrix, there are inherent tensions between diagonally opposite quadrants representing competing forms of value creation-Collaborate versus Compete, and Control versus Create. Choosing a preferred culture therefore invariably involves trade-offs, and being very strong in one dimension often creates a weakness or a blind spot in another dimension.

\subsection{Lessons for Bank Executives}

Bank chief executive officers, other senior executives, and board directors should have much to mull over on the issue of bank culture. As Federal Reserve Bank of New York President William Dudley's remarks in a 2014 speech indicate, if banks do not develop robust cultures that eliminate ethical lapses, regulators may have to step in. ${ }^{17}$ The most important takeaways for senior bank leaders are outlined here.

First, leaders should articulate a sense of higher purpose for the bank that transcends business goals but also intersects with these goals. ${ }^{18}$ Usually, a higher purpose is customer-centric, employee-centric, or designed to serve society. For example, Zingerman's, a deli in Ann Arbor, Michigan, aims to develop its employees as entrepreneurs and to give customers the best restaurant experience possible. A higher purpose for a financial services firm is to help its clients manage their finances so that they can provide better lives for their

\footnotetext{
${ }^{17}$ Dudley (2014).

${ }^{18}$ See Thakor and Quinn (2014) for a discussion of the economics of higher purpose.
} 
children and grandchildren. Howard Schultz, chairman and CEO of Starbucks, articulated a purpose for the coffee company of offering that "third place between work and home." Whatever a bank's stated objective, if it looks for the intersection of its growth strategy with that higher purpose and then ties its culture to it, the effect can be significantly positive. Research has shown that when employees truly believe that the organization is driven by a higher purpose that transcends the usual business goals and that this higher purpose actually affects the growth strategy and business decisions of the organization, agency problems are smaller and employees work harder. ${ }^{19}$

Second, leaders should do a diagnostic survey to get a sense of the bank's existing and preferred cultures.

Third, leaders can engage in a cultural-change exercise using the levers discussed in the previous section.

Fourth, leaders should be cognizant of the tensions and tradeoffs between the bank's growth strategy and preferred culture.

Finally, before finalizing a merger, leaders should consider the compatibility of the cultures of the merging banks, based on a cultural diagnosis.

\subsection{Takeaways for Bank Regulators and Supervisors}

Currently, much of the focus of bank regulators, when it comes to culture, appears to be on ensuring ethical behavior and curtailing risk taking in banks. In light of the events surrounding the crisis of 2007-09, this approach is understandable. However, the CVF provides a word of caution on this point-an excessive focus on Control can kill Create. So the key takeaways for bank supervisors are the following: First, it may be valuable to examine the practices of promotion and compensation to enhance understanding of an organization; the criteria for both will be quite informative about a bank's culture.

Second, while it is not surprising that bank supervisors emphasize the Control quadrant of the CVF more than banks themselves will, it would nonetheless be useful to consider the fact that an excessive focus on goals like predictability can hurt financial innovation, with negative consequences for growth. Thus, a balanced and nuanced approach is needed.

Third, in addition to focusing on deferred compensation as a way to encourage more long-term thinking, it may

\footnotetext{
${ }^{19}$ See Thakor and Quinn (2014) and the references therein. A customercentric higher purpose can also foster the development of a stronger "relationship banking" culture, thereby helping to reduce inefficiencies in formal intertemporal contracts with customers (see Boot and Thakor [1994] for an analysis of these in a relationship banking context), and can provide a barrier to protect relationship banking profits against competitive erosion.
}

be valuable to consider formulating guidelines based on the compensation duration measure recently developed in the literature (see, for example, Gopalan, Milbourn, Song, and Thakor [2014]).

Fourth, large and complex banks are likely to find it more challenging to have a single overarching culture, so subcultures are likely to emerge. It will be important to understand the characteristics of these subcultures.

Finally, in the case of bank mergers, the cultural compatibility of the two banks is an important determinant of success. Large mergers-like Daimler-Chrysler and Citi-Travelershave often failed owing to cultural incompatibility. ${ }^{20}$

\section{Conclusion}

In this article, I have discussed the issue of culture in banking, reviewing the relatively small literature on culture in economics and describing a CVF framework-developed in the organizational behavior field-as an example of a conceptual tool to diagnose and change culture.

Numerous important takeaways-detailed in the preceding section-emerge from this exercise. There are common lessons for all, but the messages for senior bank executives and bank regulators and supervisors are more specialized.

A strong bank culture-one that supports the bank's growth strategy and consistently influences employee behavior-can be a form of "off-balance-sheet capital" for the bank. It can reassure regulators that there will be prudent risk taking in the bank and adherence to ethical standards, while also providing the bank a basis for enhanced and sustainable value creation. This is good both for financial stability - as a useful complement to a high level of equity capital in banking-and economic growth. ${ }^{21}$

Much more research is needed on this subject. We know already that culture and trust at the national level affect trade and economic outcomes (see Guiso, Sapienza, and Zingales [2009]), and that corporate governance affects culture in organizations (see Guiso, Sapienza, and Zingales [2015]). A strong corporate culture can also be used to foster trust within banks, with positive consequences for ethical behavior and stability.

\footnotetext{
${ }^{20}$ Bouwman (2013) discusses numerous case studies of mergers that failed due to lack of cultural compatibility. Fiordelisi and Martelli (2011) empirically examine the impact of culture on the success of mergers in U.S. and European banking.

${ }^{21}$ Thakor (2014) provides an extensive review of the role of bank capital in influencing financial market outcomes and financial stability overall.
} 


\section{REFERENCES}

Acharya, V., and H. Naqvi. 2012. "The Seeds of a Crisis: A Theory of Bank Liquidity and Risk Taking over the Business Cycle." Journal of Financial Economics 106, no. 2 (November): 349-66.

Akerlof, G. A., and R. E. Kranton. 2010. IDENTity Economics: How Our Identities Shape Our Work, Wages, and Well-Being. Princeton, N.J.: Princeton University Press.

Bennett, B., R. Gopalan, and A. V. Thakor. 2015. “The Structure of Bankers' Pay.” Working paper, Washington University in St. Louis.

Boot, A., and A. V. Thakor. 1994. "Moral Hazard and Secured Lending in an Infinitely Repeated Credit Market Game.” INTERNATiONAL ECONOMic Review 35, no. 4 (November): 899-920.

1997. "Banking Scope and Financial Innovation." Review of Financial Studies 10, no. 4 (October): 1099-1131.

2000. "Can Relationship Banking Survive Competition?" Journal of Finance 55, no. 2 (April): 679-713.

Boot, A., R. Gopalan, and A. V. Thakor. 2006. “The Entrepreneur's Choice between Private and Public Ownership." Journal of Finance 61, no. 2 (April): 803-36.

2008. "Market Liquidity, Investor Participation, and Managerial Autonomy: Why Do Firms Go Private?” Journal of FinANCE 63, no. 4 (August): 2013-59.

Bouwman, C. 2013. "The Role of Corporate Culture in Mergers and Acquisitions.” In E. Perrault, ed., Mergers and Acquisitions: Practices, Performance, and Perspectives. New York: Nova Science Publishers, Inc.

Cameron, K. S., and R. E. Quinn. 2011. Diagnosing AND Changing Organizational Culture. San Francisco: John Wiley \& Sons, Inc.

Cameron, K. S., J. DeGraff, R. E. Quinn, and A. V. Thakor. 2014. Competing Values Leadership. Northampton, Mass.: Edward Elgar Publishing.

Cartwright, S., and C. Cooper. 1993. "The Role of Culture Compatibility in Successful Organizational Marriage." ACADEMY of Management Executive 7, no. 2 (May): 57-70.
Cremer, J. 1993. "Corporate Culture and Shared Knowledge." IndusTRIAl AND Corporate Change 2, no. 3 (January): 351-86.

Curry, T. J. 2014. “Keynote Remarks.” Remarks delivered at the Annual Conference of the Clearing House Association, New York City, November 21.

Deal, T. E., and A. A. Kennedy. 1982. Corporate Cultures: The Rites and Rituals of Corporate Life. Reading, Mass.: Addison-Wesley Publishing.

DeGraff, J., and S. E. Quinn. 2006. LeADING InNovation: How to Jump Start Your Organization's Growth Engine. New York: McGraw-Hill.

Dudley, W. 2014. "Enhancing Financial Stability by Improving Culture in the Financial Services Industry." Remarks delivered at the Federal Reserve Bank of New York's Workshop on Reforming Culture and Behavior in the Financial Services Industry, New York City, October 20. Available at: https://www.newyorkfed .org/newsevents/speeches/2014/dud141020a.html.

Financial Stability Board. 2014. "Guidance on Supervisory Interaction with Financial Institutions on Risk Culture: A Framework for Assessing Risk Culture.” Available at http://www.financialstabilityboard.org/2014/04/ guidance-on-supervisory-interaction-with-financial-institutions -on-risk-culture-a-framework-for-assessing-risk-culture-2/.

Fiordelisi, F., and D. Martelli. 2011. "Corporate Culture and Merger Success in Banking.” Working paper, University of Rome.

Gopalan, R., T. Milbourn, F. Song, and A. V. Thakor. 2014. "Duration of Executive Compensation.” Journal of Finance 69, no. 6 (December): 2777-2817.

Guiso, L., P. Sapienza, and L. Zingales. 2009. "Cultural Biases in Economic Exchange?” Quarterly Journal of Economics 124, no. 3 (August): 1095-1131.

—. 2015. "The Value of Corporate Culture." Journal of FinanCiAL ECONOMics 117, no. 1 (July): 60-75.

Hermalin, B. E. 2001. "Economics and Corporate Culture." In C. Cooper, S. Cartwright, and P.C. Early, eds., The International Handbook of Organization Culture and Climate. Chichester, England: John Wiley \& Sons, Ltd. 


\section{REFERENCES (CONTINUED)}

Keeley, M. 1990. "Deposit Insurance, Risk, and Market Power in Banking.” American Economic Review 80, no. 5 (December): 1183-1200.

Kreps, D. M. 1990. "Corporate Culture and Economic Theory." In J.E. Alt and K.A. Shepsle, eds., Perspectives on Positive Political Economy. Cambridge: Cambridge University Press.

Lazear, E. P. 1995. “Corporate Culture and Diffusion of Values." In H. Siebert, ed., Trends in Business Organization: Do ParTICIPATION AND COOPERATION INCREASE COMPETITIVENESS? Tübingen, Germany: J.C.B. Mohr/Paul Siebeck.

Peters, T., and R. H. Waterman, Jr. 1982. In SEARCH OF ExCELLENCE: Lessons from America's Best-Run Companies. New York: Harper \& Row.

Quinn, R. E. 1988. Beyond Rational Management: Mastering the Paradoxes and Competing Demands of High PerforMANCE. San Francisco: Jossey-Bass, Inc.

Quinn, R. E., and K. Cameron. 1983. "Organizational Life Cycles and Shifting Criteria for Effectiveness.” Management Science 29, no.1 (January): 33-51.

Quinn, R. E., and J. Rohrbaugh. 1983. "A Spatial Model of Effectiveness Criteria: Towards a Competing Values Approach to Organizational Analysis." Management Science 29, no. 3 (March): 363-377.

Song, F., and A. V. Thakor. 2010. "Financial System Architecture and the Co-evolution of Banks and Markets." The Economic Journal 120, no. 547 (September):1021-55.
Song, F., and A. V. Thakor. 2016. "Bank Culture." Working paper, Washington University in St. Louis.

ten Have, S., W. ten Have, F. Stevens, M. van der Elst, and F. Pol-Coyne. 2003. Key Management Models: The Management Tools and Practices that Will Improve Your Business. London: FT Prentice-Hall.

Thakor, A. V. 2012. "Incentives to Innovate and Financial Crises." Journal of Financial Economics 103, no. 1 (January): 130-148.

_ 2014. "Bank Capital and Financial Stability: An Economic Trade-off or a Faustian Bargain?” Annual Review of Financial ECONOMICs 6: 185-223.

Thakor, A. V., and R. E. Quinn. 2014. "The Economics of Higher Purpose." Working paper, Washington University in St. Louis and University of Michigan.

Van den Steen, E. 2010a. "On the Origin of Shared Beliefs (and Corporate Culture)." RAND Journal of ECONOMICs 41, no. 4 (Winter): 617-48.

— 2010b. "Culture Clash: The Costs and Benefits of Homogeneity.” Management Science 56, no. 10 (December): 1718-38.

The views expressed are those of the author and do not necessarily reflect the position of the Federal Reserve Bank of New York or the Federal Reserve System. The Federal Reserve Bank of New York provides no warranty, express or implied, as to the accuracy, timeliness, completeness, merchantability, or fitness for any particular purpose of any information contained in documents produced and provided by the Federal Reserve Bank of New York in any form or manner whatsoever. 